\title{
Healthy City Project: An application of data envelopment analysis
}

\author{
Sewon Park ${ }^{1,2}$ \\ Kichan Yoon ${ }^{3, *}$ \\ Munjae Lee $\mathbb{D}^{4,5, *}$
}

'Research Institute for Future Medicine, Samsung Medical Center, Seoul, 0635I, South Korea; ${ }^{2}$ Department of Medical Device Management and Research, SAIHST, Sungkyunkwan University, Seoul, 0635I, South Korea; ${ }^{3}$ School of Health Policy \& Management, Health Science College, Korea University, Seoul, South Korea; ${ }^{4}$ Department of Medical Humanities and Social Medicine, Ajou University School of Medicine, Suwon, South Korea; ${ }^{5}$ Medical Research Collaborating Center, Ajou Research Institute for Innovative Medicine, Ajou University Medical Center, Suwon, South Korea

*These authors contributed equally to this work
Correspondence: Munjae Lee Ajou University School of Medicine, 206, World Cup-ro, Yeongtong-gu, Suwon, Gyeonggi-do, South Korea

Email emunjae@ajou.ac.kr
Purpose: The importance of Korea's Healthy City Project has recently increased due to the growth of the elderly population and chronic diseases. Consequently, local governments are expanding the project to manage health at the local level; however, because local government resources are limited, efficient business operation is required. Thus, the purpose of this study is to present a plan for effective project management by developing a strategy for a Healthy City Project that is suitable for the scale of local governments.

Methods: For efficiency analysis, data were collected from the homepages of 90 local governments that are implementing the Healthy City Project in Korea, and data envelopment analysis (DEA) was conducted using both the CCR model and the BCC model. The input variables for the DEA included budget, manpower, organization, planned projects, and research education. In addition, we selected program, network, and project performance as output variables.

Results: Analysis results indicated that the CCR model identified 22 (out of 90) municipalities in which Healthy City Projects are implemented efficiently, while 68 are inefficient. The BCC model identified many more efficient regions than the CCR model; however, the difference was insignificant. Thus, the budget, manpower, planned projects, and network must be increased to improve efficiency.

Conclusion: First, to improve the efficiency of the Healthy City Project, a sufficient budget must be secured during its implementation. Second, long- and short-term plans are needed to expand the Healthy City Program. Third, networks must be created for local governments to benchmark Healthy City Projects.

Keywords: Healthy City Project, health policy, healthy city network, efficiency, DEA

\section{Introduction}

Since the mid-1970s, discussions on health promotion have been undertaken worldwide. The healthy city movement began in 1984 with the construction of the "Healthy Community" model at the "Healthy Toronto 2000" workshop in Canada. Achieving the goal of healthy cities means extending beyond a health approach and creating a healthier urban environment for members of local communities. The World Health Organization (WHO) defines healthy cities as those in which all members of the local community cooperate with each other to continuously strive to improve citizens' health and quality of life by improving their physical and social environments. The rapid urbanization of the world is considered a major challenge to health in the 21 st century. If urban development is not properly managed, communities may be at risk of health-related issues such as the increased prevalence and spread of infectious diseases, and a greater burden of noninfectious diseases. Therefore, efforts to form a systematic city plan are essential for the 
health promotion of citizens and the sustainable development of cities. Based on this background, the UN adopted the Sustainable Development Goals (SDGs) in September 2015, and efforts to achieve the SDGs are actively being undertaken in central/local governments of all world countries. The UN's SDGs are the greatest common goal of the international community to achieve 17 major objectives and 169 detailed targets by 2030 , including universal social problems such as disease, poverty, and education, as well as issues related to the global environment, climate change, and economy. SDGs comprise five main points: people, the planet, prosperity, peace, and partnership. It is similar to the Healthy City Project that began with the purpose of protecting the health of citizens while overcoming issues, including hygiene, pollution, lack of health care service supply, and disease occurrence and spread. Based on this, this study suggested the necessity of a comprehensive approach to form healthy cities at the Shanghai Consensus on Healthy Cities 2016. It emphasizes the connection between SDG goals 3: Good health and wellbeing, and SDG goals 11: Make cities inclusive, safe, resilient, and sustainable. It suggests that the health promotion of citizens can be improved through the approach of developing healthy cities to achieve SDGs and suggests a good governance principle for the healthy city approach. In addition, " 10 priority areas for healthy city activities" for the composition of healthy cities for sustainable development have been established and implemented. ${ }^{1,2}$ This Healthy City Project is currently being pursued through the creation of worldwide networks. ${ }^{3,4}$

In the case of Korea, the concept of a healthy city was first introduced in 1996 when Gwacheon-si and Gyeonggi-do, conducted a healthy city pilot project, during which local governments were encouraged to plan and implement health promotion programs for their communities. To form a healthy city, local governments were guided in establishing an infrastructure for health promotion, which included the construction of community sports facilities, the creation of trails and shelters, no-smoking clinics, river improvement projects, traffic noise regulation, the implementation of children's obesity schools, and detailed projects designed for urban life. In addition, as a principle of the Healthy City Project, all citizens should be able to access the Healthy City Program, which should promote local communities' participation in environmental and social change. ${ }^{5}$ With the growth of the elderly population and chronic diseases, citizens find it difficult to perform all functions of life in the community. Accordingly, at the local government level, the Healthy City Project has been introduced to improve citizens' quality of life by improving the physical and social determinants of urban health. However, because the resources for Healthy City Projects are limited, it seems that the efficient operation of projects is necessary to achieve the goal of promoting citizens' health. ${ }^{6,7}$

Healthy cities comprise a field of policy-related activity. Therefore, the need for performance evaluations has been emphasized to determine whether basic municipalities have had a significant effect on the health of citizens, who are the final consumers of the policy, through public policies. Performance management for healthy cities can improve outcomes for local communities, thus supporting more desirable decision-making. Citizens' demand for public policies, such as healthy cities, is increasing; basic municipalities are striving to provide higher quality policies through the performance management of public policies. Accordingly, it has become increasingly necessary to measure the efficiency of basic municipalities' public policies and to conduct a comparative analysis between them. ${ }^{8,9}$

Meanwhile, when conducting research on healthy cities, De Leeuw ${ }^{10}$ defined the basic concept of healthy cities implemented by local communities. In addition, while defining the scope and purpose of healthy cities, she provided basic data for their evaluation. Kegler et al ${ }^{11}$ conducted a case analysis of healthy cities in California. To promote citizens' health, they advocated strengthening the organization dedicated to facilitating healthy cities and offering residents the opportunity to participate in decision-making. Furthermore, Nam et al ${ }^{12}$ analyzed the characteristics of healthy Korean city projects. Previous studies reported that the Healthy City Project had established networks for each local government, but that performance differed based upon the head of the local government's level of interest in healthy cities. In addition, it was determined that only approximately half of the regions implementing the Healthy City Project conducted selfevaluations. Status analysis, case analysis, and evaluation indexes for healthy cities have been active topics of research, whereas very few studies have measured the effectiveness of Healthy City Projects. Moreover, most studies that conduct performance evaluations focus only on the output aspect; thus far, no studies have combined the aspects of input, process, and output.

Hence, in this study, we intend to analyze the effectiveness of Healthy City Projects for basic municipalities executing healthy cities using data envelopment analysis (DEA). We thereby intend to develop a measure to improve the efficiency of Healthy City Projects and to present baseline data that can be used to systematically 
establish a Healthy City Project strategy tailored to regional conditions.

\section{Materials and Methods Research Model}

In this study, we conduct DEA to analyze the effectiveness of Healthy City Projects. Through DEA, it is possible to evaluate the performance of a specific decision-making unit (DMU) that provides multiple inputs and outputs, and is widely used to measure the efficiency of public institutions. ${ }^{13}$ Performance evaluation of public sector operation and management is generally used for costbenefit analysis, ratio analysis, and production function analysis. This evaluation method has limitations in that performance factors that cannot be quantified must be converted into monetary values, and weights must be arbitrarily assigned for the summation of individual ratios. Unlike the private sector, where evaluation is accurately conducted based on the market in efficiency evaluation method, the public sector has no clear criteria, making accurate evaluation difficult. Therefore, most of the public sector is being evaluated relatively, and the public sector mainly uses DEA to measure relative efficiency. ${ }^{14}$

Widely used for measuring efficiency of the public sector because it does not need to use arbitrary weights, DEA can analyze measured input and output factors as they are. In addition, it has been widely used to evaluate the efficiency of sectors for which it is difficult to evaluate because no specific standards exist, such as government agencies, public corporations, and nonprofit organizations. DEA is an evaluation method that compares and analyzes efficiency scores, and can find the most favorable weight for each decision-making unit by examining the relative ratio between input and output factors. Based on this, it is possible to provide the basis for setting the input and calculation standards of resources used when performing projects in the public sector. In addition, DEA compares the performance between inefficient and efficient organizations and suggests a reference group similar to input and output for inefficient organizations to suggest ways to improve their efficiency. ${ }^{15}$ If used in the Healthy City Project, it is believed that it will be possible to draw improvement plans for it by comparing its efficiency by region, thus, identifying areas that can be benchmarked and identifying the cause of inefficiency.

The Healthy City Project refers to the establishment of a city that deals directly with social determinants of health and improves the health and quality of life of citizens by improving health inequality. In the Healthy City Project, citizens' health is the priority of decision making. It fosters a clean and safe physical environment, accessible optimal health care service, and high health levels for residents. Factors that determine health include not only health care, but also society, culture, environment, and welfare. The Healthy City Project is divided into three areas-wider determinants, lifestyle, and health impact-each of which comprises preconditions and main activities. Wider determinants include public health, transportation, and climate change. Lifestyle comprises prevention of chronic diseases, smoking and drinking activities, and physical activity. Health impact includes topics related to health levels, socioeconomic levels, and inequality between regions. The preconditions of each of the three areas consist of leadership, vision and strategy, structure and process, and network. The main activities comprise policies, programs, and projects. Based on this, the policy to improve the living environment of an entire city is implemented. ${ }^{16}$

For example, to improve the activity of residents, projects such as the improvement of trails and campaigns for residents' participation are needed. Such projects require a budget, manpower, and a dedicated organization. In addition, public works are needed to create a physically and socially healthy environment, and employees require education to develop them. On the other hand, one of the main goals of the Healthy City Project is to cooperate and coordinate with multi-partial and multi-partial organizations to have a cooperative governance structure. ${ }^{17}$ Through multi-sector cooperation, health promotion programs are being developed in areas such as improving smoking and drinking behavior, fostering walking activity, and chronic disease management. Currently, it is important for residents to decide the priority of the local Healthy City Project and to participate in the decision-making process. If sports classrooms are operated as part of the Healthy City Project, cooperation with related departments, citizen opinion surveys, and citizen participation is required. Since the Healthy City Project maintains civic participation and empowerment as its core goals, the development of Healthy City Project programs is based on the results of community health and citizen opinion surveys. In other words, a Healthy City Project should be easy for citizens to participate in, and should be able to precipitate a change in citizens' behavior to improve health. Therefore, citizen participation in programs related 
to Healthy City Projects is considered a very important factor in their evaluation. ${ }^{18}$

In addition, by establishing a network among healthy cities, we are creating a forum in which health problems can be solved and the capacity of policymakers can be strengthened. The WHO has encouraged cities to build mutual networks since the start of the Healthy City Project. As an essential evaluation condition for joining the Secretariat of the Alliance for Healthy Cities (AFHC) or the Korea Healthy Cities Partnership (KHCP), the internal and external network activities of cities should be described. To facilitate Healthy City Projects, official partnerships in various sectors should be formed. Further, to actively promote them, they should be evaluated through research tailored to the characteristics of each local government, consultation through citizen proposals or policy contests, and overseas training and conferences to expand and share the Healthy City Project. Based on the composition and major factors of the Healthy City Project, in this study, the input variables were budget, manpower, dedicated organization, number of planned projects, and training education invested in the project; output variables included program, network, and project performance of a Healthy City Project, whereby its efficiency is measured.

DEA can be divided into the Charnes, Cooper, and Rhodes (CCR) and the Banker, Charnes, and Cooper (BCC) models. The CCR model assumes a constant return to scale (CRS) in which the output also increases according to a constant ratio when all input elements are proportionally increased. In contrast, the BCC model assumes a variable return to scale (VRS) in which the output decreases or increases proportionally as the input element increases. ${ }^{19}$ In this study, we used the CCR and BCC models, and analyzed the efficiency scores of the collected data using Excel 2013. In addition, the SPSS 25.0 program was used to verify regional differences in Healthy City Projects. The data necessary for analysis were collected from the websites of each basic municipality implementing the Healthy City Project. The areas of local governments and specific research models used in the analysis were as follows (Figures 1 and 2).

\section{Variable Selection Input Variables}

Budget

Regarding the budget for Healthy City Projects, cities and provinces are currently securing their own funding and promoting themselves. In addition, the budget is comprehensively invested to constitute a health promotion project or a healthy city, rather than a budget for Healthy City Projects only. As a result, it is difficult to define the scope of the budget to be input in Healthy City Projects, and there is a large variation in budgets, depending on the cities and provinces. In this study, it was classified based on the budget scale to promote healthy cities in terms of budget execution status by city and province. ${ }^{20}$

\section{Human Resources}

It was determined that if a local government executing the Healthy City Project has a dedicated healthy city department, it is typically staffed by three to five people. However, in parallel with the Health Promotion Project, if no dedicated department exists, the project is implemented concurrently with other projects, in addition to having dedicated personnel. By securing manpower, it is possible to promote Healthy City Projects and incite the active participation of local communities. Therefore, we intended to use the personnel in dedicated departments for Healthy City Projects as an input variable. ${ }^{21}$

\section{Organization}

The dedicated organizations of the Healthy City Projects were classified according to whether they were pursued separately from health promotion or other projects. The existence of dedicated organizations in charge of Healthy City Projects can be judged as evidence that they can be continuously managed through a systematically capable organization. ${ }^{22}$ Moreover, through dedicated organizations, both detailed and long-term development plans can be established for Healthy City Projects. In this study, whether a dedicated organization was formed within the local organization to support the Healthy City Project was used as an input variable.

\section{Number of Planned Projects}

To successfully promote Healthy City Projects, it is necessary to analyze the current situation through the creation of urban health profiles at the local government level. An urban health profile is a basic requirement to join the Alliance for Healthy Cities. It is used as baseline data for establishing a plan for a Healthy City Project by providing comprehensive basic information on the health and environmental conditions of the local community. Through the creation of an urban health profile, a local government demonstrates its intention to promote 


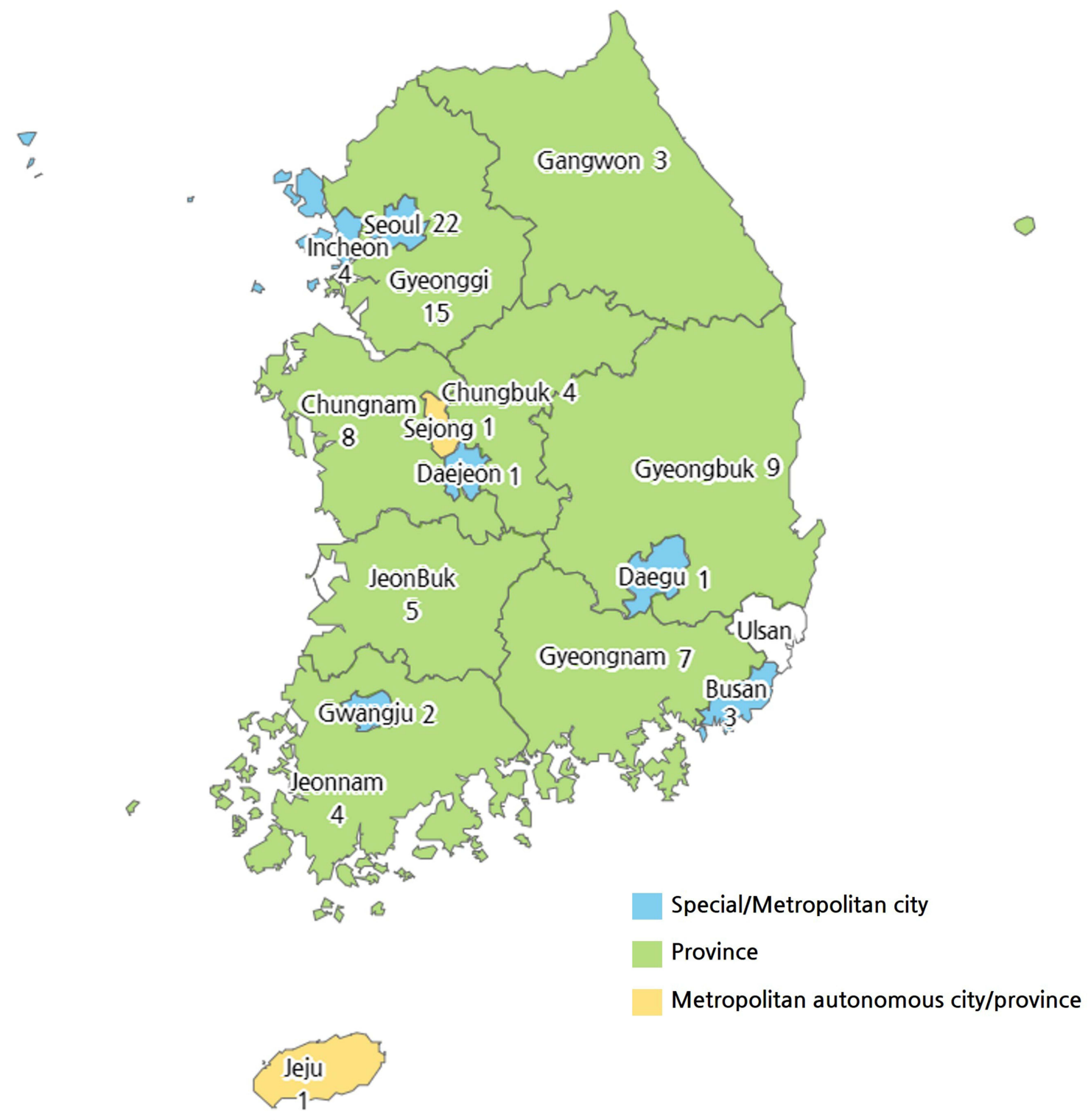

Figure I Regions used for analysis.

\begin{tabular}{|c|}
\hline Input \\
\hline Budget \\
Human Resources \\
Organization \\
Number of planned projects \\
Training \\
\hline
\end{tabular}

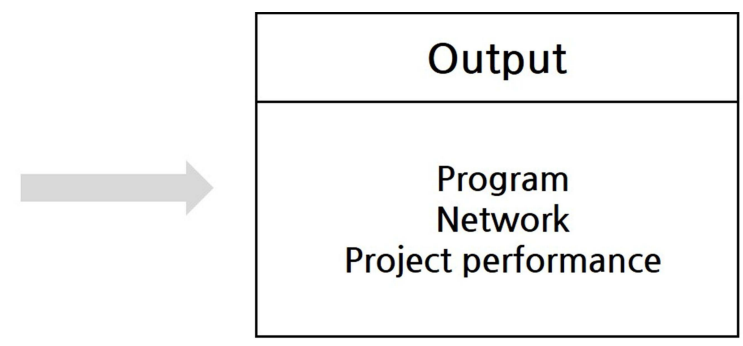

Figure 2 Research model.

Healthy City Projects in the long term. Therefore, it seems that local governments established long-term plans for a healthy city based on their urban health profile and were carrying out specific projects. In this study, the number of planned projects was used as an input variable based on the creation of urban health profiles, annual and long-term plans for healthy cities, and advisory committees. ${ }^{23}$ 


\section{Training}

To successfully implement the Healthy City Project, the capability of the organization's members must be reinforced. To strengthen their capabilities, activities - including self-seminars for those involved in Healthy City Projects, technical support, and research activities with local universities - are conducted. Most local governments participating in the domestic Healthy City Project perform capability-strengthening activities through self-seminars. In addition, active exchanges with other regions are required for effective benchmarking of Healthy City Projects. Moreover, it is time-consuming to understand and participate in a Healthy City Program; thus, it seems that an educational program for local government employees and residents is also necessary. ${ }^{24}$ Accordingly, external, research, and educational activities were used as the input variables.

\section{Output Variables \\ Program}

For the evaluation of healthy cities, the annually updated content of the Healthy City Program was reviewed, and the results were analyzed. We attempted to grasp the current status of Healthy City Programs that are actually being promoted by each local government and to divide them by type to input them as output variables. The representative programs of the Healthy City Project are classified into categories, including the foundation construction of healthy cities, healthy life practices, healthy living sites, healthy environment creation, and health equity. In the early stages of the Healthy City Project, the focus is on establishing the foundation for healthy cities. After it began in earnest, the proportion of practical Healthy City Projects, such as the creation of a healthy living site and healthy living practice programs, seemingly increased. ${ }^{25}$ In other words, local governments are making efforts to implement Healthy City Projects that are suitable for the characteristics of their region by providing developed programs and services to citizens. Accordingly, the extent to which citizens actually use these healthy city-related programs also plays an important role. Therefore, the Healthy City Project and the number of users were set as output variables.

\section{Network}

To promote the health of citizens, healthy cities strive to enhance living conditions by improving health determinants at a wide range of levels, including local communities, cities, and counties. Since they value change at the local community level and aim to create a physical and social environment for healthy cities, cooperation between sectors is necessary. Thus, for the effective implementation of a healthy city, it is necessary to achieve cooperation between sectors through the integration of related sectors. In addition, the WHO's European Healthy Cities Network presents official and informal networks as items for healthy city evaluation to change urban health. ${ }^{26,27}$ Accordingly, by forming networks between healthy cities by region, activities such as information exchange, experience sharing, mutual establishment of support systems, sharing of achievements and ideas, and the formation of partnerships are executed. On this basis, partnerships by sector and networks by region were set as output variables.

\section{Project Performance}

The WHO has presented several recommendations for local governments to implement Healthy City Projects. It considers that political support from local communities, information sharing with citizens, and involvement of mass media are necessary, and that domestic and international networking, research and analysis of healthy cities by linking them with universities, and opinion gathering with all groups in the community are also needed. ${ }^{28}$ Local governments are voluntarily implementing Healthy City Projects based on these recommendations; if they have no experience in promoting such projects, they are frequently initiated through consultation or project support from health care experts of neighboring universities. In addition, long-term studies are needed to evaluate the feasibility and suitability of Healthy City Projects. Sometimes, education on Healthy City Projects is provided by publicly announcing research results through seminars. Since it is necessary to incite local residents to participate in the project, contest exhibits are held from time to time to announce a healthy city and increase the degree of participation. Meanwhile, to establish the basis for Healthy City Projects and to strengthen their capabilities, international exchanges between cities in many other countries are conducted to promote scientific project planning. The results of Healthy City Projects were thereby defined as research activities, external activities, contest projects, and international exchanges, which were also set as output variables.

\section{Results}

\section{Technical Statistics}

The means of the input and output variables of the basic municipalities that have implemented the Healthy City Project were analyzed. Among the input variables, the 
mean of the Healthy City Project budget was 763,672 thousand won; the number of employees was 3.61 ; the dedicated organization was 1.12 units; the number of planned projects was 10.63 units; and the frequency of training education was 1.76 times. Output variables included 5.16 programs and 1.52 networks, and the value for project performance was 5.22 units (Table 1).

\section{Efficiency Score and Reference Group}

DEA was conducted using five input variables and three output variables to analyze the efficiency of Healthy City Projects by a basic municipality. First, an analysis of the CCR model that assumes constant returns revealed that most of the regions were inefficient. Only 22 (24.4\%) of the 90 basic municipalities analyzed were carrying out their Healthy City Projects efficiently. If examined by administrative district, only eight special/metropolitan cities, 13 provinces, and one metropolitan autonomous city/province were effectively implementing Healthy City Projects. For special/metropolitan cities, Yongsan-gu, Dongdaemun-gu, Eunpyeong-gu, Busanjin-gu, Gijanggun, Suseong-gu, Yeonsu-gu, and Gwangsan-gu were found to be effective in implementing the program. Among the provinces, Suwon-si, Anseong-si, Goyang-si, Wonju-si, Yanggu-gun, Jecheon-si, Geumsan-gun, Cheonan-si, Dangjin-si, Gunsan-si, Namwon-si, Jangheung-gun, and Namhae-gun were found to be effective in implementing the program. Only Sejong-si was found to be effective in the case of metropolitan autonomous cities/provinces. In addition, as the reference groups for other municipalities, the places with the highest number of references appeared in the following order: Dongdaemun-gu (28 times), Yeonsu-gu (28 times), and

Table I Descriptive Statistics of Input and Output Variables

\begin{tabular}{|l|l|c|c|}
\hline \multicolumn{2}{|l|}{ Variable } & Mean & $\begin{array}{c}\text { Standard } \\
\text { Deviation }\end{array}$ \\
\hline \multirow{4}{*}{$\begin{array}{l}\text { Input } \\
\text { variable }\end{array}$} & Budget (I000 won) & 763,672 & $4,216,204$ \\
\cline { 2 - 4 } & Manpower & 3.61 & 4.10 \\
\cline { 2 - 4 } & Dedicated organization & 1.12 & 0.56 \\
\cline { 2 - 4 } & Number of planned projects & 10.63 & 18.86 \\
\cline { 2 - 4 } & Training education & 1.76 & 7.60 \\
\hline \multirow{2}{*}{$\begin{array}{l}\text { Output } \\
\text { variable }\end{array}$} & Program & 5.16 & 4.61 \\
\cline { 2 - 4 } & Network & 1.52 & 3.08 \\
\cline { 2 - 4 } & Project performance & 5.22 & 8.59 \\
\hline
\end{tabular}

Eunpyeong-gu (19 times), where districts in the special/ metropolitan cities were referenced (Table 2).

Next, the BCC model analysis was conducted while assuming a change in returns. Of the 90 basic municipalities, $23(25.6 \%)$ were found to be conducting Healthy City Projects efficiently, which is similar to the CCR results. Specifically, seven special/metropolitan cities, 15 provinces, and one metropolitan autonomous city or province were effectively implementing Healthy City Projects. In the case of special/metropolitan cities, Yongsan-gu, Eunpyeong-gu, Busanjin-gu, Gijang-gun, Suseong-gu, Yeonsu-gu, and Gwangsan-gu were found to be efficient in implementing the program; unlike the CCR results, Dongdaemun-gu appeared inefficient. In view of this, it is judged that Dongdaemun-gu has not achieved economies of scale in project operations. In terms of provinces, Suwon-si, Anseong-si, Goyang-si, Yanggu-gun, Jecheon-si, Geumsangun, Seosan-si, Dangjin-si, Hongseong-gun, Gunsan-si, Namwon-si, Jangheung-gun, Goryeong-gun, Uljin-gun, and Namhae-gun were found to be effective in implementing the program. The CCR analysis indicated that Wonju-si was a region that effectively implemented Healthy City Projects, but the $\mathrm{BCC}$ analysis showed that it was not efficient. Wonju-si also seems to have failed to achieve economies of scale on the assumption of return changes. In addition, Seosan-si, Hongseong-gun, and Uljin-gun were found to be efficient regions in the BCC analysis, unlike the CCR analysis results. Considering this, we can recognize that if the input variable is increased, the Healthy City Project can be efficiently implemented. In the meantime, as the reference groups for other municipalities, the regions with the most reference numbers appeared to be Yeonsu-gu (19 times), Eunpyeong-gu (17 times), and Yongsan-gu (16 times); regions in the special/metropolitan cities showed a large number of references (Table 3).

The DEA result showed that it is necessary to improve efficiency through a decrease in input variables or an increase in output variables for the municipalities, thus indicating that the Healthy City Project is inefficient. In the DEA, this is expressed as a slack value, which means it can be efficiently changed when at least that amount of input and output variables is additionally input. The CCR model assumes a constant return; in order for inefficient municipalities to change their efficiency, better performance in areas such as budget, manpower, number of planned projects, training education, and network, was required for efficient operation. The budget should be increased by an average of 930.763 thousand won, manpower by an average of 0.86 persons, number 
Table 2 CCR Efficiency Score

\begin{tabular}{|c|c|c|c|c|}
\hline \multirow[t]{2}{*}{ Municipality } & \multirow[t]{2}{*}{ Total } & \multicolumn{3}{|c|}{ Administrative District } \\
\hline & & Special/Metropolitan City & Province & $\begin{array}{l}\text { Metropolitan } \\
\text { Autonomous } \\
\text { City/Province }\end{array}$ \\
\hline $\begin{array}{l}\text { Efficient } \\
\text { municipality }\end{array}$ & $22(24.4 \%)$ & 8 & 13 & I \\
\hline $\begin{array}{l}\text { Inefficient } \\
\text { municipality }\end{array}$ & $68(75.6 \%)$ & 25 & 42 & I \\
\hline $\begin{array}{l}\text { Efficient } \\
\text { Municipality } \\
\text { name }\end{array}$ & $\begin{array}{l}\text { Each } 22 \\
\text { municipality - } \\
\text { Reference } \\
\text { number }\end{array}$ & $\begin{array}{c}\text { Yongsan-gu-13, Dongdaemun-gu-28, } \\
\text { Eunpyeong-gu-19, Busanjin-gu-9, Gijang- } \\
\text { gun-2, Suseong-gu-13, Yeonsu-gu-28, } \\
\text { Gwangsan-gu-0 }\end{array}$ & $\begin{array}{l}\text { Suwon-si-4, Anseong-si-0, Goyang-si-0, } \\
\text { Wonju-si-9, Yanggu-gun-12, Jecheon-si-5, } \\
\text { Geumsan-gun-3, Cheonan-si-8, Dangjin-si-II, } \\
\text { Gunsan-si-3, Namwon-si-7, Jangheung-gun } \\
\text {-10, Namhae-gun-0 }\end{array}$ & Sejong-si-0 \\
\hline
\end{tabular}

Table 3 BCC Efficiency Score

\begin{tabular}{|c|c|c|c|c|}
\hline \multirow[t]{2}{*}{ Municipality } & \multirow[t]{2}{*}{ Total } & \multicolumn{3}{|c|}{ Administrative District } \\
\hline & & Special/Metropolitan City & Province & $\begin{array}{l}\text { Metropolitan } \\
\text { Autonomous } \\
\text { City/Province }\end{array}$ \\
\hline $\begin{array}{l}\text { Efficient } \\
\text { municipality }\end{array}$ & $23(25.6 \%)$ & 7 & 15 & I \\
\hline $\begin{array}{l}\text { Inefficient } \\
\text { municipality }\end{array}$ & 67 (74.4\%) & 26 & 40 & I \\
\hline $\begin{array}{l}\text { Efficient } \\
\text { Municipality } \\
\text { name }\end{array}$ & $\begin{array}{c}\text { Each } 17 \\
\text { municipality - } \\
\text { Reference } \\
\text { number }\end{array}$ & $\begin{array}{c}\text { Yongsan-gu-16, Eunpyeong-gu- I7, } \\
\text { Busanjin-gu-4, Gijang-gun-6, Suseong-gu } \\
\text {-9, Yeonsu-gu-19, Gwangsan-gu-0 }\end{array}$ & $\begin{array}{l}\text { Suwon-si-6, Anseong-si-0, Goyang-si-0, } \\
\text { Yanggu-gun-14, Jecheon-si-3, Geumsan-gun-8, } \\
\text { Seosan-si-0, Dangjin-si-7, Hongseong-gun- I, } \\
\text { Gunsan-si-8, Namwon-si-7, Jangheung-gun- I5, } \\
\text { Goryeong-gun-0, Uljin-gun-0, Namhae-gun-0 }\end{array}$ & Sejong-si-0 \\
\hline
\end{tabular}

of planned projects by an average of 2.38, and training education by an average of 2 units. In addition, it was determined that networks should be increased by an average of 0.86 and project performance by an average of 0.30 . The number of basic municipalities, which requires an increased budget, was 30, accounting for the largest part, followed by 26 for planned projects, 18 for manpower, and 18 for training education. It is deemed that it would be helpful to increase the budget for the efficiency of Healthy City Projects. In the case of output variables, the number of municipalities that required the increased establishment of a network was 41, accounting for the largest number, followed by project performance (18) and programs (3). In other words, it seems that the establishment of a network, rather than an increase in programs or performance, would be helpful in ensuring the efficiency of Healthy City Projects (Table 4).

The BCC model assumes a return change; it seems that for inefficient municipalities to be effectively changed, higher results in areas such as budget, manpower, number of planned projects, training education, and network are required to achieve efficient operation, as in the CCR model. The budget should increase by an average of $1,082,968$ thousand won, manpower by an average of 16 people, the number of planned projects by an average of 3.32 , and training education by an average of 0.31 . In addition, we found that the network should increase by an average of 0.96 units and business performance by an average of 0.44 . The BCC model assumes that the Healthy 
Table 4 Inefficient Municipalities' Slack Value Mean

\begin{tabular}{|c|c|c|c|c|c|c|c|c|c|}
\hline \multicolumn{2}{|l|}{ DEA } & \multicolumn{5}{|c|}{ Input Variable } & \multicolumn{3}{|c|}{ Output Variable } \\
\hline & & Budget & $\begin{array}{l}\text { Man- } \\
\text { Power }\end{array}$ & $\begin{array}{c}\text { Dedicated } \\
\text { Organization }\end{array}$ & $\begin{array}{c}\text { Number of } \\
\text { Planned Projects }\end{array}$ & $\begin{array}{l}\text { Training } \\
\text { Education }\end{array}$ & Program & $\begin{array}{l}\text { Net- } \\
\text { Work }\end{array}$ & $\begin{array}{c}\text { Project } \\
\text { Performance }\end{array}$ \\
\hline \multirow[t]{2}{*}{ CCR } & Municipality & 30 & 18 & 6 & 26 & 18 & 3 & 41 & 18 \\
\hline & Mean & 930,763 & 0.86 & 0.01 & 2.38 & 2.00 & 0.03 & 0.86 & 0.30 \\
\hline \multirow[t]{2}{*}{$\mathrm{BCC}$} & Municipality & 29 & 16 & 4 & 23 & 17 & 13 & 49 & 25 \\
\hline & Mean & $1,082,968$ & 1.06 & 0.00 & 3.32 & 0.31 & 0.29 & 0.94 & 0.44 \\
\hline
\end{tabular}

City Project achieves economies of scale, where the slack value appears higher than that of the CCR model, excluding training education. It is therefore judged that economies of scale have not been achieved in the Healthy City Projects currently being implemented by the municipalities. Furthermore, the number of municipalities in need of budget increases appeared to be 29 , accounting for the largest share, followed by the number of planned projects (23), training education (17), and manpower (16). As for the output variable, 49 municipalities needed to increase network construction, accounting for the largest share, followed by project performance (25) and programs (13), which suggests that network construction is necessary for efficient Healthy City Projects.

\section{Analysis of Mean Difference in Healthy Cities by Region}

The Kruskal-Wallis test, a nonparametric statistical technique, was conducted to compare and analyze the efficiency of each basic municipality that is implementing the Healthy City Project. The analysis revealed that manpower, number of planned projects, and networks were statistically significant, and the difference in efficiency scores was not statistically significant in both the CCR and $\mathrm{BCC}$ models. Among the output variables of program, network, and project performance, the mean rankings of special/metropolitan cities were $62.94,34.65$, and 56.00, respectively, suggesting that the mean ranking of provinces was the highest. Furthermore, in the case of the number of planned projects, the mean rankings of special/ metropolitan cities were 58.53, 38.28, and 29.00, respectively, showing that the mean ranking of metropolitan autonomous cities/provinces was the highest. If we examine the mean ranking of networks among the output variables, the mean ranking of special/metropolitan cities was
56.09; that of provinces was 38.44; and that of metropolitan autonomous cities/provinces was 65.00 , which showed that the mean ranking of provinces was the highest (Table 5).

\section{Discussion}

The Healthy City Project is being implemented as part of a regionally-based health promotion policy. In addition, because it is a project in which budget and manpower are invested in each region, performance evaluation is required. ${ }^{29,30}$ The goal of the Healthy City Project is to make systematic efforts to support the health of citizens. However, it is a challenge to evaluate a Healthy City Project because health as a process is more important than health as a result. Healthy City Projects differ greatly between regions, depending on the local population, socioeconomic conditions, and physical environment. Depending on local demand, the project can focus on improving the health of the underprivileged, or it can focus on improving the environment for health promotion of the middle class or higher. Therefore, the implementation of the Healthy City Project can provide an appropriate program to improve the health of citizens only when it is efficiently implemented by identifying the needs of citizens and environmental factors. Despite the importance of measuring the efficiency of a healthy city, existing research has focused on fragmentary case studies, status analysis, and development of evaluation indicators. Therefore, it is noted that no existing studies have analyzed the efficiency of Healthy City Projects by municipality and analyzed the difference in efficiency of municipalities implementing Healthy City Projects using DEA. The analysis results were as follows.

First, DEA revealed that most regions implementing the Healthy City Project were inefficient. In the CCR model, there were 22 efficient municipalities, and in the 
Table 5 Mean Difference by Region

\begin{tabular}{|c|c|c|c|c|c|}
\hline \multicolumn{2}{|l|}{ Variable } & \multirow{2}{*}{$\begin{array}{c}\text { Special/Metropolitan } \\
\text { City } \\
47.92\end{array}$} & \multirow{2}{*}{$\begin{array}{c}\text { Province } \\
44.67\end{array}$} & \multirow{2}{*}{$\begin{array}{c}\text { Metropolitan Autonomous Cityl } \\
\text { Province }\end{array}$} & \multirow{2}{*}{$\begin{array}{c}X^{2} \\
1.211(2)\end{array}$} \\
\hline Input & Budget & & & & \\
\hline Varlabie & Manpower & 62.94 & 34.65 & 56.00 & $25.665 * * *(2)$ \\
\hline & Dedicated organization & 45.05 & 45.15 & 62.75 & $2.121(2)$ \\
\hline & $\begin{array}{c}\text { Number of planned } \\
\text { projects }\end{array}$ & 58.53 & 38.28 & 29.00 & $13.290 * * *(2)$ \\
\hline & Training education & 42.67 & 47.49 & 37.50 & $1.029(2)$ \\
\hline \multirow{3}{*}{$\begin{array}{l}\text { Output } \\
\text { variable }\end{array}$} & Program & 52.08 & 41.21 & 55.00 & $3.943(2)$ \\
\hline & Network & 56.09 & 38.44 & 65.00 & $|3.04| * * *(2)$ \\
\hline & Project performance & 52.09 & 41.18 & 55.50 & $3.984(2)$ \\
\hline \multirow[t]{2}{*}{ Efficiency } & CCR & 46.74 & 44.38 & 55.75 & $0.483(2)$ \\
\hline & $\mathrm{BCC}$ & 46.20 & 44.90 & 50.50 & $0.126(2)$ \\
\hline $\mathrm{N}$ & & 33 & 55 & 2 & \\
\hline
\end{tabular}

Note: $*^{* * *} \mathrm{p}<0.001$.

BCC model, there were 23 efficient municipalities. In other words, most of the 90 regions featured in the analysis were operating the Healthy City Project inefficiently. This is similar to previous research results that reported that each municipality is spending its budget for the operation of the Healthy City Project, but the contents and structure of the project are not organized. ${ }^{31}$ Thirty-seven percent of the municipalities in Korea advocate for a healthy city. They have a dedicated department and staff to carry out the Healthy City Project and invest the necessary budget for operation. However, based on the results of this study, the resources invested in promoting Healthy City Projects are not being used efficiently enough to show results.

This seems to be because the concepts of the Healthy City Project and health promotion project are used interchangeably. While a healthy city is a broader concept than health promotion, in practice, there is a tendency to conceive of the Healthy City Project as a part of the health promotion project. For this reason, the boundaries of health promotion projects, such as public health center projects, conducted in the region are ambiguous and the projects are carried out in a mixed manner. ${ }^{32}$ Because of this, it is difficult to understand how the Healthy City Project is being promoted in municipalities, and there seems to be a limit to its strategic implementation.
Specifically, in order to address the aging population, the increase in chronic diseases, and the widening gap in health levels between regions, municipalities are claiming the necessity of the Healthy City Project. However, it is not included in the Health Plan, which is Korea's national health plan. Therefore, it seems that it is difficult to efficiently carry out the Healthy City Project because it is being employed as a one-time project without meeting the main goal of a healthy city for sustainable development.

Second, as a result of analyzing the slack value to improve efficiency, it was determined that budget, manpower, number of planned projects, and training education among input variables in both the CCR and BCC models need to be increased; in the case of output variables, it was determined that increases in networks and project performance are crucial. To implement a Healthy City Project, it is necessary to secure a sufficient budget, attract citizens' participation, and recruit capable manpower. However, the results of this study indicate that successful implementation of the Healthy City Project is difficult because the budget, manpower, and various Healthy City Project plans are not sufficiently secured during the project's implementation. Specifically, Healthy City Projects must be planned in accordance with regional characteristics, such as demographic structure and medical infrastructure, and for this purpose, urban health profiles must be prepared to join the 
Korea Healthy Cities Partnership. To carry out sustainable Healthy City Projects, urban health profiles must be updated, yet research indicates the most have not been. Thus, it appears that city-optimized Healthy City Projects have not been carried out. Furthermore, because healthy cities seek to improve the physical and social environment of the city beyond the existing health care system, the participation of the city's leadership, local community, and networks, and capability reinforcement are required. Because Healthy City Projects are implemented based on the history, context, and structure of each region, it is expected that networking between regions that have similar contexts can improve the performance of the Healthy City Project.

Third, an analysis of the gap in Healthy City Projects by municipality revealed that the manpower to be dedicated to the projects is larger at the province level. Upon examination of the results of the efficiency analysis, it was determined that there were more provincial levels in areas that efficiently carried out Healthy City Projects. It seems that more manpower is being dedicated to Healthy City Projects to promote health in provincial units with relatively sizable populations of elderly people and poor medical infrastructures, rather than in municipalities. Specifically, it was determined that networks were active among the output variables in province unit areas. It appears that the Healthy City Program is benchmarking through regional cooperation to carry out the Healthy City Project. In other words, it seems that health policies related to Healthy City Projects are being promoted by actively encouraging exchanges with external regions to revitalize Healthy City Projects.

Meanwhile, in metropolitan cities, there was less manpower and fewer planned projects to be factored into Healthy City Projects. It appears that, in metropolitan cities, it is difficult to attain the manpower to implement Healthy City Projects because health promotion projects are not differentiated from them and are ubiquitous. Specifically, it would seem that if an organization is dedicated to facilitating a healthy city, a Healthy City Project can be successfully carried out; however, it seems difficult to secure manpower due to a lack of dedicated organizations. Because manpower is not secured, long-term plans and programs to implement a healthy city are not established in various ways.

This study is limited in that it does not consider the implementation period of Healthy City Projects for each basic municipality. Out of the 93 areas implementing
Healthy City Projects, for 39 areas, less than 10 years have passed since implementation. At least 10 years are required for the evaluation of Healthy City Projects, and it seems that many inefficient areas have emerged because these periods were not considered. If the elements that appeared inefficient were to be supplemented based on the results of the study, the effective implementation of Healthy City Projects would be possible in the future. The study confirmed that the Healthy City Project was carried out inefficiently in most municipalities. To improve efficiency, overall input resources, such as budget, manpower, dedicated organizations, number of planned projects, and training and education, must be increased. Specifically, benchmarking is often undertaken in metropolitan cities, however, even though they are the benchmarking targets, they lack manpower and projects. This is a factor that hinders the effectiveness of the Healthy City Project in Korea. To improve the project, each municipality must reorganize the department and manpower allocated to it and promote the health of the municipality by participating in inter-sectoral and inter-regional cooperation. Thereafter, related programs must be increased.

\section{Conclusion}

Based on the results of this study, the following efforts are necessary to improve the efficiency of Healthy City Projects.

First, for an efficient and sustainable Healthy City Project, a healthy city-related support law that can be clearly distinguished from health promotion projects is needed. Healthy City Projects have the characteristics of public policy, and in order for public policy to succeed, it is necessary to secure a sufficient budget, establish feasible goals, and provide a basis for implementing them. The concept of a healthy city is broader than that of health promotion. However, there are many cases where there is no specific budget for the Healthy City Project, and where a Healthy City Project is carried out under the health promotion project. This is because there is no law related to healthy cities; thus, it is impossible to establish a policy based on evidence.

Second, the role of the central government should be strengthened to ensure continuous management, such as the implementation and evaluation of the Healthy City Project. It takes at least 10 years to affect a change in the health level of the population to implement a healthy city. Therefore, it is necessary for the local community to establish a physical and social environment conducive 
to establishing and implementing the long-term goal of solving urban health problems. However, current domestic Healthy City Projects are being led by municipalities, and no management is undertaken after their implementation. As municipalities independently invest their budgets, it seems that health inequality is worsening in cities in areas with weak financial conditions, as they reveal low activity in Healthy City Projects. Therefore, administrative and financial support from the central government is necessary to expand the overall infrastructure input of Healthy City Projects. Regions that have achieved a certain level of performance, such as a high level of project performance by expanding budgets, increased manpower, and number of programs, should receive support from the central government for the implementation and continuation of Healthy City Projects if their health is recognized by the central government. For this to happen, such cities must be designated and evaluated. In addition, in the case of domestic Healthy City Projects, specific project details, project periods, and related organizations are insufficient. A plan or work guideline must be established to implement Healthy City Projects. City health profiles, which are the basis for the development of urban public policies, should be continuously updated so that health determinants can be analyzed. Through this, it will be possible to systematically establish long-term and short-term plans to improve the health of citizens.

Third, a dedicated department in charge of the Healthy City Project must be established and activate a network through cooperation within other sectors. The European Healthy Cities Network not only spreads and exchanges new policies and best practices related to healthy cities but also contributes to raising the interest and volition of policy makers by transforming healthy cities into a political discourse. However, in Korea, organizations in charge of Healthy City Projects are insufficient, thus, governance for cooperation between sectors is not established. In Healthy City Projects, health is the most emphasized theme in all policies, and for this, collaboration between ministries is essential. In addition, a network for various activities, such as basic international-national-local cooperation and strategic planning for the health of the entire city, must be established. To this end, local governments implementing Healthy City Projects should form a dedicated department and expand exchanges with various member cities by allocating trained manpower. It is expected that an integrated health plan will be established through the Healthy City Project network, and that national and regional Healthy City Projects will be consistently promoted based on this. Specifically, it is difficult to consistently implement a Healthy City Project in each region due to significant differences in the socio-economic conditions of cities and the degree of development in implementing the project. Therefore, it is expected that the Healthy City Project can be effectively implemented if appropriate cases are selected and benchmarked among regions with similar health determinants through the establishment of a healthy city network.

\section{Abbreviations}

WHO, World Health Organization; DEA, data envelopment analysis; DMU, decision-making unit; CRS, constant return to scale; VRS, variable return to scale; CCR, Charnes, Cooper and Rhodes; BCC, Banker, Charnes and Cooper.

\section{Acknowledgments}

We would like to thank the support of the Ministry of Education of the Republic of Korea and the National Research Foundation of Korea (NRF-2019S1A5A2A0 3040304).

\section{Disclosure}

The authors report no conflicts of interest in this work.

\section{References}

1. Ramirez-Rubio O, Daher C, Fanjul G, et al. Urban health: an example of a "health in all policies" approach in the context of SDGs implementation. Global Health. 2019;15(1):1-21. doi:10.1186/s12992-019-0529-z

2. Valencia SC, Simon D, Croese S, et al. Adapting the sustainable development goals and the new urban agenda to the city level: initial reflections from a comparative research project. Int J Urban Sustain Dev. 2019;11(1):4-23. doi:10.1080/19463138.2019.1573172

3. Davies JK, Kelly M. Healthy Cities: Research and Practice. Routledge; 2014.

4. Ashton J, Grey P, Barnard K. Healthy cities-WHO's new public health initiative. Health Promot Int. 1986;1(3):319-324. doi:10.1093/ heapro/1.3.319

5. Kim H. Healthy City Kwachon 21 project: a community health promotion programme in Korea. Asia Pac $J$ Public Health. 2000;12:S67-70.

6. Lee M, Park S, Yoon K. Does health promotion program affect local resident'emotions? Int J Environ Res Public Health. 2019;16(4):549. doi:10.3390/ijerph16040549

7. Lee M, Yoon K. A study on the research trend of Healthy City Project in Korea using social network analysis. Health Soc Welfare Rev. 2018;38(1):459-488. doi:10.15709/hswr.2018.38.1.459

8. Lo Storto C. The trade-off between cost efficiency and public service quality: a non-parametric frontier analysis of Italian major municipalities. Cities. 2016;51:52-63. doi:10.1016/j.cities.2015.11.028 
9. Blank JLT. Measuring the performance of local administrative public services. BRQ Bus Res Q. 2018;21(4):251-261. doi:10.1016/j. brq.2018.09.001

10. De Leeuw E. Global and local (glocal) health: the WHO healthy cities programme. Glob Change Hum Health. 2001;2(1):34-45. doi:10.1023/A:1011991014805

11. Kegler MC, Norton BL, Aronson R. Achieving organizational change: findings from case studies of 20 California healthy cities and communities coalitions. Health Promot Int. 2008;23(2):109-118. doi:10.1093/heapro/dan009

12. Nam EW, Lee A, Moon JY, Song YL-A, Dhakal S. Analyze the characteristics of the healthy cities projects using HP-Source.net in Korea. Int J Health Promot Educ. 2015;53(5):244-256. doi:10.1080/ 14635240.2015.1010655

13. Kim S, Yoon K. An analysis of the educational gap between local governments: an application of Data Envelopment Analysis (DEA) Korea Soc Policy Rev. 2012;19(2):99-136. doi:10.17000/ kspr.19.2.201206.99

14. Tomaževič N, Seljak J, Aristovnik A. TQM in public administration organisations: an application of data envelopment analysis in the police service. Total Qual Manag Bus Excell. 2016;27(1112):1396-1412. doi:10.1080/14783363.2015.1007861

15. Zhou H, Yang Y, Chen Y, Zhu J. Data envelopment analysis application in sustainability: the origins, development and future directions. Eur J Oper Res. 2018;264(1):1-16. doi:10.1016/j.ejor.2017.06.023

16. Corburn J. Equitable and healthy city planning: towards healthy urban governance in the century of the city. In: Healthy Cities. Springer; 2017:31-41.

17. Nichols LM, Taylor LA. Social determinants as public goods: a new approach to financing key investments in healthy communities. Health Aff. 2018;37(8):1223-1230. doi:10.1377/hlthaff.2018.0039

18. Lenzi A, Capolongo S, Ricciardi G, et al. New competences to manage urban health: health city manager core curriculum. Acta Bio Med Atenei Parmensis. 2020;91(Suppl 3):21. doi:10.23750/ abm.v91i3-S.9430

19. Banker RD. Estimating most productive scale size using data envelopment analysis. Eur J Oper Res. 1984;17(1):35-44. doi:10.1016/ 0377-2217(84)90006-7
20. Oh Y-M, Kim H-J, Hong K-S. Evaluation of the Healthy Cities in Korea (2008-2010). Health Educ Promot. 2011;28(3):99-111.

21. Kim J. Principles for evaluating healthy cities. Health Educ Promot. 2012;29(4):67-81.

22. Milio N. Healthy cities: the new public health and supportive research. Health Promot Int. 1990;5(4):291-297. doi:10.1093/heapro/5.4.291

23. Green G. Intersectoral planning for city health development. $J$ Urban Health. 2012;89(2):247-257. doi:10.1007/s11524-011-9642-x

24. Dooris M, Heritage Z. Healthy cities: facilitating the active participation and empowerment of local people. J Urban Health. 2013;90 (1):74-91. doi:10.1007/s11524-011-9623-0

25. Nam E-W, Moon J-Y, Lee A. Evaluation of healthy city project using SPIRIT checklist: Wonju city case. Korean J Health Educ Promot. 2010;27(5):15-25.

26. Stern R, Green J. A seat at the table? A study of community participation in two healthy cities projects. Crit Public Health. 2008;18 (3):391-403. doi:10.1080/09581590801959337

27. Kenzer M. Healthy cities: a guide to the literature. Public Health Rep. 2000;115(2-3):279. doi:10.1093/phr/115.2.279

28. Kegler MC, Twiss JM, Look V. Assessing community change at multiple levels: the genesis of an evaluation framework for the California healthy cities project. Health Educ Behav. 2000;27 (6):760-779. doi:10.1177/109019810002700610

29. Jackson PM. Public service performance evaluation: a strategic perspective. Public Money Manag. 1993;13(4):9-14. doi:10.1080/ 09540969309387783

30. DeGroff A, Schooley M, Chapel T, Poister TH. Challenges and strategies in applying performance measurement to federal public health programs. Eval Program Plann. 2010;33(4):365-372. doi:10.1016/j.evalprogplan.2010.02.003

31. Kim K, Yoo S, Kang E. The relationship between healthy city and health promotion and the directions for a revision of the National Health Promotion Act. Korean J Health Educ Promot. 2019;36 (5):87-98. doi:10.14367/kjhep.2019.36.5.87

32. Lee M, Yoon K. Effects of the health promotion programs on happiness. Sustainability. 2020;12(2):528. doi:10.3390/su12020528
Risk Management and Healthcare Policy

\section{Publish your work in this journal}

Risk Management and Healthcare Policy is an international, peerreviewed, open access journal focusing on all aspects of public health, policy, and preventative measures to promote good health and improve morbidity and mortality in the population. The journal welcomes submitted papers covering original research, basic science, clinical \& epidemiological studies, reviews and evaluations, guidelines, expert opinion and commentary, case reports and extended reports. The manuscript management system is completely online and includes a very quick and fair peer-review system, which is all easy to use. Visit http://www.dovepress.com/testimonials.php to read real quotes from published authors. 